\title{
NGHIÊN CỬU ĐÁNH GIÁ ẢNH HƯỞNG CỦA BIẾN ĐỔI KHÍ HẬU ĐẾN DÒNG CHẢY ĐẾN HỒ A VƯƠNG
}

\author{
Nguyễn Văn Khánh ${ }^{1}$, Trần Thục ${ }^{2}$
}

Tóm tắt: Nghiên cứu đã ứng dụng mô hình NAM để tính toán và đánh giá ảnh hưởng của Biến đổi khi hậu đến dòng chảy đến hồ A Vuơng. Kết quả hiệu chỉnh và kiểm định chỉ ra sư tuơng đồng về pha và biên độ dao động giữa lư luợng tính toán và thực đo. Tù̀ kết quả hiệu chỉnh và kiểm định, làm cơ sở để tính toán dụ báo sụ thay đổi dòng chảy đến hồ trong các thời kỳ tuoơng lai. Kết quả tính toán dòng chảy đến hồ theo các thời kỳ tuoong lai cho thấy dòng chảy đến hồ có sư thay đổi theo các tháng của tùng mùa: tháng $V$ là tháng chịu tác động mạnh mẽ nhất của biến đổi khí hậu trong các tháng mùa cạn, còn thàng XI là tháng chịu tác động mạnh mẽ nhất trong các tháng mùa lũ. Mức độ ảnh hường của biến đổi khí hậu đến dòng chảy mùa cạn ít hơn so với mùa lũ.

Từ khóa: MIKE NAM, A Vưong, Biến đổi khi hậu.

Ban Biên tập nhận bài: 08/2/2019 Ngày phản biện xong: 20/03/2019 Ngày đăng bài: 25/04/2019

\section{1. Đặt vấn đề}

Biến đổi khí hậu (BĐKH) là một trong những thách thức lớn nhất đối với nhân loại. Thiên tai và các hiện tượng khí hậu cực đoan đang gia tăng ở hầu hết các nơi trên thế giới. BĐKH thực sự đã làm cho bão, lũ, hạn hán ngày càng nghiêm trọng. Theo kịch bản $\mathrm{BĐKH}$ và nước biển dâng cho Việt Nam (Bộ TNMT, 2016), đến cuối thế kỷ 21, nhiệt độ trung bình ở Việt Nam có thể tăng $4^{0} \mathrm{C}$ và mực nước biển có thể dâng lên $1 \mathrm{~m}$ [1]. Số liệu quan trắc cũng cho thấy, trong giai đoạn 1958 - 2014, nhiệt độ đã tăng khoảng $0,62^{\circ} \mathrm{C}$, nhiệt độ cực trị tăng ở hầu hết các vùng, mưa cực đoan tăng ở Nam - Trung Bộ, Tây Nguyên, hạn hán xuất hiện thường xuyên hơn. Sự thay đổi chế độ mưa dẫn đến thay đổi chế độ dòng chảy của các lưu vực sông.

Theo cơ quan môi trường Châu Âu EEA năng lượng đóng một vai trò cơ bản trong việc hỗ trợ tất cả các khía cạnh của cuộc sống hiện đại. Mặt khác, các nguồn cung cấp năng lượng và nhu cầu năng lượng rất nhạy cảm với những thay đổi về khí hậu, đặc biệt là nhiệt độ. Tần số ngày xuất hiện thời tiết khắc nghiệt, bao gồm sóng nhiệt, hạn hán và bão có khả năng tăng đặt ra những thách thức lớn cho các nhà máy điện. Đặc biệt, hiệu suất và sản lượng nhà máy điện có thể bị ảnh hưởng bởi sự gia tăng nhiệt độ hoặc giảm lượng nước phục vụ làm mát. Sản xuất thủy điện cũng có thể bị ảnh hưởng bởi sự gia tăng trầm tích vào các hồ chứa do tăng xói mòn và hậu quả của BĐKH.

Để có thể đề xuất những giải pháp ứng phó với $\mathrm{BĐKH}$ đối với lưu vực hồ thủy điện $\mathrm{A}$ Vương nhằm giảm thiểu các thiệt hại do $\mathrm{BĐKH}$ gây ra, cần thiết phải có những nghiên cứu về sự thay đổi của các yếu tố tác động đến hồ thủy điện A Vương như lượng mưa, bốc hơi, dòng chảy... trong điều kiện BĐKH.

Mục đích của nghiên cứu này: (1) Nghiên cứu ứng dụng mô hình thủy văn MIKE NAM tính toán lưu lượng đến hồ A Vương; (2) Đánh giá ảnh hưởng của biến đổi khí hậu đến dòng chảy đến hồ hồ A Vương.

\section{Phương pháp nghiên cứu và thu thập tài liệu}

\subsection{Giới thiệu vị trí nghiên cúu}

Công trình thuỷ điện $\mathrm{A}$ Vương nằm trên sông A Vương thuộc huyện Hiên, tỉnh Quảng Nam. Sông $\mathrm{A}$ Vương là một trong những sông nhánh của sông Bung thuộc hệ thống Vũ Gia - Thu Bồn, bắt nguồn từ phía Tây Bắc thuộc biên giới Việt - Lào có độ cao $1400 \mathrm{~m}$ và hợp lưu với sông Bung cách tuyến nhà máy khoảng $9 \mathrm{~km}$ về phía 
thượng lưu.

Địa hình lưu vực sông $\mathrm{A}$ Vương thuộc loại địa hình vùng núi có các đỉnh núi cao từ $900 \mathrm{~m}$ (tại phân thuỷ phía nam) đến 1450 m (tại phân thuỷ phía bắc) với mức độ chia cắt rất mạnh, các sườn núi thường rất dốc và thung lũng rất sâu. Hướng chính của lưu vực là hướng đón gió Đông Nam. Lưu vực công trình thuỷ điện $\mathrm{A}$ Vương nằm ở phía đông dải Trường Sơn, trong vùng khí hậu Trung Trung Bộ. Chế độ khí hậu ở đây có hai đặc điểm chính là; mùa đông đã bớt lạnh rõ rệt và lượng mưa khá phong phú song phân bố không đều. Tổn thất gia tăng khi xây dựng hồ chứa $\mathrm{A}$ Vương, được đánh giá dựa trên cơ sở tài liệu dòng chảy tính toán, tài liệu mưa trên lưu vực, tài liệu bốc hơi tại Đà Nẵng. Lượng mưa trong mùa mưa chiếm hơn $90 \%$ tổng lượng mưa năm. Nhưng theo chỉ tiêu phân mùa trung bình thì mùa mưa ở đây vào tháng 5 và từ tháng 9 đến tháng 11 với đỉnh mưa là tháng 10 , trong 3 tháng mưa chính (tháng $9,10,11$ ) lượng mưa chiếm hơn $50 \%$ lượng mưa toàn năm. Số ngày mưa trong các tháng mùa mưa từ 10 - 20 ngày, tổng số ngày mưa trong năm khoảng 80 - 160 ngày.

Tài liệu lũ của trạm thuỷ văn trên hệ thống sông Vũ Gia Thu Bồn cho thấy sự xuất hiện của lũ lớn nhất hàng năm trên hệ thống sông này là tương đối phức tạp, theo chỉ tiêu phân mùa thì mùa lũ từ tháng 10 đến tháng 12 , nhưng có một số năm lũ lớn nhất trong năm lại xuất hiện vào tháng 5,9 là những tháng đầu của mùa mưa phụ và mùa mưa chính. Do địa hình dốc lên lũ thường lên rất nhanh, đỉnh lũ khá lớn. Các trận lũ lớn trên sông $\mathrm{A}$ Vương đều xuất hiện cùng thời gian với các trận lũ lớn trên sông Vu Gia - Thu Bồn. Điều này chứng tỏ rằng những trận lũ lớn nhất hàng năm trên lưu vực đều do một hiện tượng thời tiết gây mưa lớn trên diện rộng sinh ra còn những trận lũ nhỏ hơn thì có thời gian xuất hiện khác nhau là do những hiện tượng thời tiết gây mưa lũ khác nhau sinh ra.

\subsection{Thu thâp tài liệu}

Trong nghiên cứu này một số dữ liệu đầu vào được sử dụng như sau:
Số liệu vể khí tượng: Sử dụng số liệu mưa tại các trạm Sông Bung 2, A Vương, Hiên và số liệu bốc hơi tại trạm Trà My làm đầu vào cho mô hình MIKE NAM.

Số liệu thủy văn: Sử dụng số liệu trích lũ và số liệu lưu lượng thực đo về hồ A Vương trong các năm 2010, 2011, 2013 để phục vụ hiệu chỉnh và kiểm định mô hình.

Số liệu địa hình: Sử dụng bản đồ số độ cao (DEM 30) cho toàn bộ lưu vực phục vụ cho việc phân chia lưu vực trong mô hình MIKE NAM.

\subsection{Phuoong pháp nghiên cúu}

Các phương pháp được sử dụng trong nghiên cứu này như: phương pháp thống kê, xử lý số liệu dùng trong việc phân tích và xử lý số liệu đầu vào của bài toán; phương pháp mô hình toán dùng mô hình thủy văn dòng chảy (MIKE NAM) để diễn toán dòng chảy đến lưu vực nghiên cứu.

Mô hình NAM được xây dựng tại Khoa Thuỷ văn Viện Kỹ thuật Thuỷ động lực và Thuỷ lực thuộc Đại học Kỹ thuật Đan Mạch năm 1982. NAM là chữ viết tắt của cụm từ tiếng Đan Mạch "Nedbør - Afstrømnings - Models" có nghĩa là mô hình mưa rào dòng chảy. Cấu trúc mô hình NAM được xây dựng trên nguyên tắc các hồ chứa theo chiều thẳng đứng và các hồ chứa tuyến tính, gồm có 5 bể chứa theo chiều thẳng đứng như hình 1 .

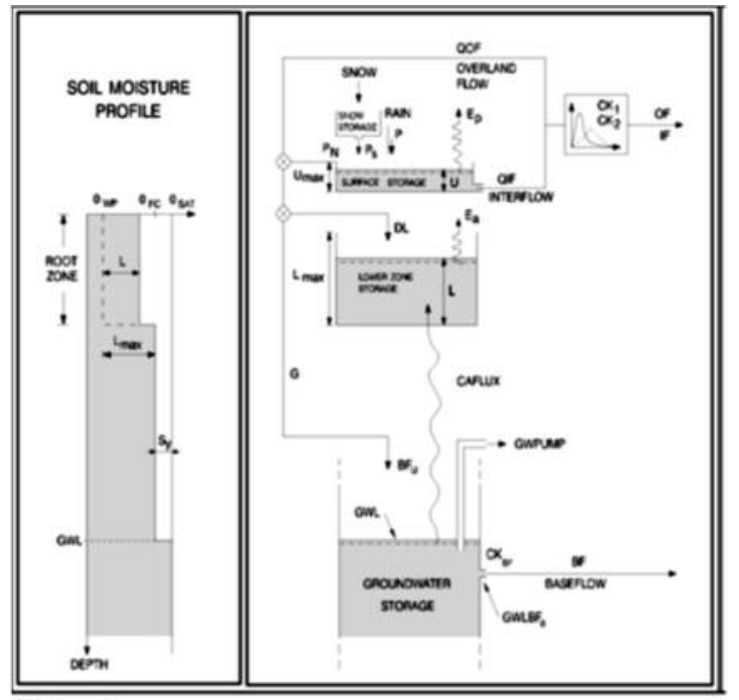

Hình 1. Cấu trúc mô hình NAM 
Bể chứa tuyết tan: được kiểm soát bằng các điều kiện nhiệt độ. Đối với điều kiện khí hậu nhiệt đới ở nước ta thì không xét đến bể chứa này.

Bể chứa mặt: lượng nước ở bể chứa này bao gồm lượng nước mưa do lớp phủ thực vật chặn lại, lượng nước đọng lại trong các chỗ trũng và lượng nước trong tầng sát mặt. Giới hạn trên của bể chứa này được ký hiệu bằng $\mathrm{U}_{\max }$. Lượng ẩm trữ trên bề mặt của thực vật, lượng nước điền trũng trên bề mặt lưu vực và lượng nước trong tầng sát mặt được đặc trưng bởi lượng trữ ẩm bề mặt. Giới hạn trữ nước tối đa trong bể chứa này được ký hiệu bằng $U_{\max }$. Lượng nước $U$ trong bể chứa mặt sẽ giảm dần do bốc hơi, do thất thoát theo phương nằm ngang (dòng chảy sát mặt). Khi lượng nước này vượt quá ngưỡng $\mathrm{U}_{\max }$ thì một phần của lượng nước vượt ngưỡng $\mathrm{P}_{\mathrm{n}}$ này sẽ chảy vào suối dưới dạng chảy tràn trên bề mặt, phần còn lại sẽ thấm xuống bể ngầm. Lượng nước ở bể chứa mặt bao gồm lượng nước mưa do lớp phủ thực vật chặn lại, lượng nước đọng lại trong các chỗ trũng và lượng nước trong tầng sát mặt.

Bể chứa tầng dưới: Bể này thuộc tầng rễ cây, là lớp đất mà thực vật có thể hút ẩm để thoát ẩm. Giới hạn trên của lượng ẩm tối đa trong bể chứa này được kí hiệu là $\mathrm{L}_{\max }$. Lượng ẩm của bể chứa sát mặt được đặc trưng bằng đại lượng $\mathrm{L}$, phụ thuộc vào lượng tổn thất thoát hơi của thực vật. Lượng ẩm này cũng ảnh hưởng đến lượng nước sẽ đi xuống bể chứa ngầm để bổ sung nước ngầm. Tỷ số $\mathrm{L} / \mathrm{L}_{\max }$ biểu thị trạng thái ẩm của bể chứa

Bốc thoát hơi nước của thực vật được ký hiệu là $\mathrm{E}_{\mathrm{a}}$, tỷ lệ với lượng bốc thoát hơi bể chứa mặt $\left(\mathrm{E}_{\mathrm{p}}\right)$. Bốc thoát hơi nước thực vật là để thỏa mãn nhu cầu bốc hơi của bể chứa mặt. Nếu lượng ẩm U trong bể chứa mặt nhỏ hơn bốc thoát hơi thực đo thì bể chứa mặt bị bốc hơi hết. Lượng bốc hơi còn thiếu sẽ được bổ sung từ tầng dưới $\left(\mathrm{E}_{\mathrm{a}}\right)$. Ban đầu nó sẽ bốc hơi lượng ẩm trong đất ở tầng dưới còn thừa ở các giai đoạn trước nếu thiếu nó tiếp tục bốc hơi lượng nước chứa trong đất ở tầng dưới. Do đó lượng bốc thoát hơi $\left(\mathrm{E}_{\mathrm{a}}\right)$ phụ thuộc vào lượng trữ ẩm có trong đất.

Bể chứa nước ngầm: Lượng nước bổ sung cho dòng chảy ngầm phụ thuộc vào độ ẩm của đất trong tầng rễ cây. Mưa hoặc tuyết tan trước tiên đi vào bể chứa mặt. Lượng nước $U$ trong bể chứa mặt liên tục tiêu hao do bốc thoát hơi và thấm ngang để tạo thành dòng chảy sát mặt. Khi lượng nước $U$ vượt quá giới hạn $U_{\max }$, phần lượng nước thừa sẽ tạo thành dòng chảy tràn để tiếp tục chảy ra sông, phần còn lại sẽ thấm xuống các bể chứa tầng dưới và bể chứa tầng ngầm.

Lượng cấp nước ngầm được chia ra thành 2 bể chứa: bể chứa nước ngầm tầng trên và bể chứa nước ngầm tầng dưới. Hoạt động của hai bể chứa này như các hồ chứa tuyến tính với các hằng số thời gian khác nhau. Nước trong hai bể chứa này sẽ tạo thành dòng chảy ngầm.

Dòng chảy tràn và dòng chảy sát mặt được diễn toán qua một hồ chứa tuyến tính thứ nhất. Sau đó, tất cả các thành phần dòng chảy được cộng lại và diễn toán qua một hồ chứa tuyến tình thứ hai. Cuối cùng sẽ được dòng chảy tổng cộng tại cửa ra.

* Các yếu tố chính ảnh hưởng đến dòng chảy trong mô hình NAM [3]

Lượng trữ bề mặt: Lượng ẩm bị giữ lại bởi thực vật cũng như được trữ trong các chỗ trũng trên tầng trên cùng của bề mặt đất được coi là lượng trữ bề mặt. $U_{\max }$ biểu thị giới hạn trên của tổng lượng nước trong lượng trữ bề mặt. Tổng lượng nước $U$ trong lượng trữ bề mặt liên tục bị giảm do bốc hơi cũng như do thấm ngang. Khi lượng trữ bề mặt đạt đến mức tối đa, một lượng nước thừa $\mathrm{P}_{\mathrm{N}}$ sẽ gia nhập vào sông với vai trò là dòng chảy tràn trong khi lượng còn lại sẽ thấm vào tầng thấp bên dưới và tầng ngầm.

Lượng trữ tầng thấp hay lượng trữ tầng rễ cây: Độ ẩm trong tầng rễ cây, lớp đất bên dưới bề mặt đất, tại đó thực vật có thể hút nước để bốc thoát hơi đặc trưng cho lượng trữ tầng thấp. $\mathrm{L}_{\text {max }}$ biểu thị giới hạn trên của tổng lượng nước trữ trong tầng này. Độ ẩm trong lượng trữ tầng thấp cung cấp cho bốc thoát hơi thực vật. Độ ẩm trong tầng này điều chỉnh tổng lượng nước gia nhập vào lượng trữ tầng ngầm, thành phần dòng chảy 
mặt, dòng sát mặt và lượng gia nhập lại.

Bốc thoát hơi nước: Nhu cầu bốc thoát hơi đầu tiên được thoả mãn từ lượng trữ bề mặt với tốc độ tiềm năng. Nếu lượng ẩm $U$ trong lượng trữ bề mặt nhỏ hơn yêu cầu $\left(\mathrm{U}<\mathrm{E}_{\mathrm{p}}\right)$ thì phần còn thiếu được coi rằng là do các hoạt động của rễ cây rút ra từ lượng trữ tầng thấp theo tốc độ thực tế $\mathrm{E}_{\mathrm{a}}$. $\mathrm{E}_{\mathrm{a}}$ tương ứng với lượng bốc hơi tiềm năng và biến đổi tuyến tính theo quan hệ lượng trữ ẩm trong đất, $\mathrm{L} / \mathrm{L}_{\max }$, của lượng trữ ẩm tầng thấp.

$$
E_{a}=\left(E_{p}-U\right) \frac{L}{L_{\max }}
$$

Dòng chảy mặt: Khi lượng trữ bề mặt đã tràn, $\mathrm{U}>\mathrm{U}_{\max }$, thì lượng nước thừa $\mathrm{P}_{\mathrm{N}}$ sẽ gia nhập vào thành phần dòng chảy mặt.Thông số QoF đặc trưng cho phần nước thừa $\mathrm{PN}$ đóng góp vào dòng chảy mặt. Nó được giả thiết là tương ứng với $\mathrm{P}_{\mathrm{N}}$ và biến đổi tuyến tính theo quan hệ lượng trữ ẩm đất, $\mathrm{L} / \mathrm{L}_{\max }$, của lượng trữ ẩm tầng thấp.

$$
\mathrm{Q}_{\mathrm{OF}}= \begin{cases}C Q_{O F} \frac{L / L_{\max }}{1-T_{O F}} P_{N} & \text { nếu } L / L_{\max }>T_{O F} \\ 0 & \text { nếu } L / L_{\max } \leq T_{O F}\end{cases}
$$

Trong đó: $\mathrm{CQ}_{\mathrm{OF}}$ là hệ số dòng chảy tràn trên mặt đất $\left(0 \leq \mathrm{CQ}_{\mathrm{OF}} \leq 1\right)$, $\mathrm{T}_{\mathrm{OF}}$ là giá trị ngưỡng của dòng chảy tràn $\left(0 \leq \mathrm{T}_{\mathrm{OF}} \leq 1\right)$.

Phần lượng nước thừa $\mathrm{P}_{\mathrm{N}}$ không tham gia vào thành phần dòng chảy tràn sẽ thấm xuống lượng trữ tầng thấp. Một phần trong đó, $\Delta \mathrm{L}$, của nước có sẵn cho thấm, $\left(\mathrm{P}_{\mathrm{N}}-\mathrm{Q}_{\mathrm{OF}}\right)$, được giả thiết sẽ làm tăng lượng ẩm $\mathrm{L}$ trong lượng trữ ẩm tầng thấp. Lượng ẩm còn lại, $\mathrm{G}$, được giả thiết sẽ thấm sâu hơn và gia nhập lại vào lượng trữ tầng ngầm.

Dòng chảy sát mặt: Sự đóng góp của dòng chảy sát mặt, $\mathrm{Q}_{\mathrm{IF}}$, được giả thiết là tương ứng với U và biến đổi tuyến tính theo quan hệ lượng chứa ẩm của lượng trữ tầng thấp.

$$
Q_{\text {I F }}=\left\{\begin{array}{rr}
\left(C K_{I F}\right)^{-1} \frac{\frac{L}{L_{\max }}-T_{I F}}{1-T_{I F}} U \text { nếu } L / L_{\max }>T_{I F} \\
0 \quad \text { nếu } L / L_{\max } \leq T_{I F}
\end{array}\right.
$$

Trong đó $\mathrm{CK}_{\mathrm{IF}}$ là hằng số thời gian dòng chảy sát mặt và $T_{\mathrm{IF}}$ là giá trị ngưỡng tầng rễ cây của dòng sát mặt $\left(0 \leq \mathrm{T}_{\mathrm{IF}} \leq 1\right)$.

Diễn toán dòng chảy mặt và dòng sát mặt: Dòng sát mặt được diễn toán qua chuỗi hai hồ chứa tuyến tính với cùng một hằng số thời gian
$\mathrm{CK}_{12}$. Diễn toán dòng chảy mặt cũng dựa trên khái niệm hồ chứa tuyến tính nhưng với hằng số thời gian có thể biến đổi

$$
C K= \begin{cases}C K_{12} \text { nếu } O F<O F_{\text {min }} & \text { nếu } O F<O F_{\text {min }} \\ C K_{12}\left(\frac{O F}{O F_{M I N}}\right)^{-\beta} & \text { nếu } O F<O F_{\min }\end{cases}
$$

Trong đó $\mathrm{OF}$ là dòng chảy tràn $(\mathrm{mm} / \mathrm{hr}) \mathrm{OF}_{\text {min }}$ là giới hạn trên của diễn toán tuyến tính $(=0,4$ $\mathrm{mm} /$ giờ), và $\beta=0,4$. Hằng số $\beta=0,4$ tương ứng với việc sử dụng công thức Manning để mô phỏng dòng chảy mặt. Theo phương trình trên, diễn toán dòng chảy mặt được tính bằng phương pháp sóng động học, và dòng chảy sát mặt được tính theo mô hình NAM như dòng chảy mặt (trong lưu vực không có thành phần dòng chảy mặt) được diễn toán như một hồ chứa tuyến tính.

Luợng gia nhập nước ngầm: Tổng lượng nước thấm $\mathrm{G}$ gia nhập vào lượng trữ nước ngầm phụ thuộc vào độ ẩm chứa trong đất trong tầng rễ cây.

$$
\mathrm{G}=\left\{\begin{array}{l}
\left(P_{N}-Q_{O F}\right) \frac{\frac{L}{L_{\max }}-T_{G}}{1-T_{G}} \text { nếu } L / L_{\max }>T_{G} \\
0 \quad \text { nếuL } / L_{\max } \geq T_{G}
\end{array}\right.
$$

Trong đó $\mathrm{T}_{\mathrm{G}}$ là giá trị ngưỡng tầng rễ cây đối với lượng gia nhập nước ngầm $\left(0 \leq \mathrm{T}_{\mathrm{G}} \leq 1\right)$.

Độ ẩm chưa trong đất: Lượng trữ tầng thấp biểu thị lượng nước chứa trong tầng rễ cây.Sau khi phân chia mưa giữa dòng chảy mặt và dòng thấm xuống tầng ngầm, lượng nước mưa còn lại sẽ đóng góp vào lượng chứa ẩm $(\mathrm{L})$ trong lượng trữ tầng thấp một lượng $\Delta \mathrm{L}$.

$$
\Delta L=P_{N}-Q_{C F}-G
$$

Dòng chảy co bản: Dòng chảy cơ bản BF từ lượng trữ tầng ngầm được tính toán như dòng chảy ra từ một hồ chứa tuyến tính với hằng số thời gian $\mathrm{CK}_{\mathrm{BF}}$.

\subsection{Thiết lập mô hình MIKE NAM}

Số liệu đầu vào cho mô hình bao gồm số liệu mưa được thu thập từ quá trình đo đạc tại các trạm Sông Bung 2, A Vương, Hiên và số liệu bốc hơi lấy từ trạm Trà My. Số liệu phục vụ cho mô hình được lấy tại thời điểm các trận lũ xảy ra vào năm 2011 và 2013. Tiến hành phân chia lưu vực lớn thành các lưu vực con để tiến hành tính toán, 
hoàn nguyên dữ liệu bằng cách xử lý bản đồ, chia lưu vực trên ArcGis dựa vào DEM 30 m của lưu vực sông.

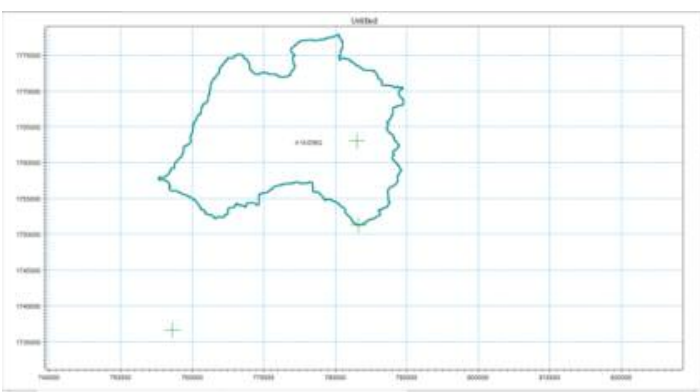

Hình 2. So đồ chia lưu vực

\section{Kết quả và thảo luận}

\subsection{Hiêu chỉnh và kiểm định mô hình}

Theo đề xuất kỹ thuật đã được phê duyệt, nhằm mục đích sử dụng mô đun MIKE-NAM trong bộ mô hình MIKE để tính toán chính xác dòng chảy đến hồ, việc đầu tiên là phải hiệu chỉnh và kiểm định mô hình với các số liệu thực đo, từ đó xác định bộ thông số của mô hình NAM cho tiểu lưu vực.

Số liệu dùng để hiệu chỉnh và kiểm định mô hình: số liệu mưa trích lũ và số liệu lưu lượng thực đo về hồ A vương năm 2010, năm 2011 và năm 2013.

\section{a) Hiệu chỉnh mô hình}

Trong khi hiệu chỉnh, các thông số mô hình được điều chỉnh bằng cách thử sai kết hợp với hiệu chỉnh tự động để đạt tới giá trị gần đúng. Các giá trị gần đúng này được coi là hệ số điển hình để xác định dòng chảy trong lưu vực. Sau khi hiệu chỉnh các thông số, kết quả so sánh giữa số liệu tính toán và thực đo như sau:

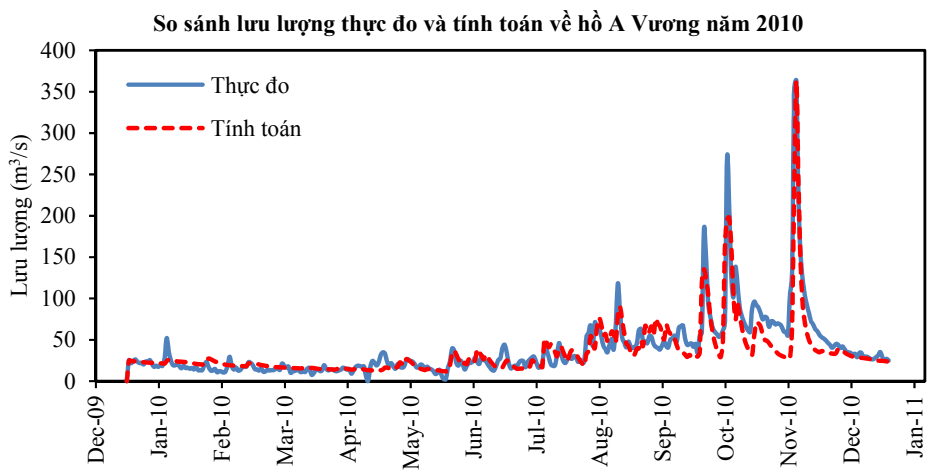

Hình 3. Kết quả so sánh giũa đường quá trình tính toán và thục đo năm 2010

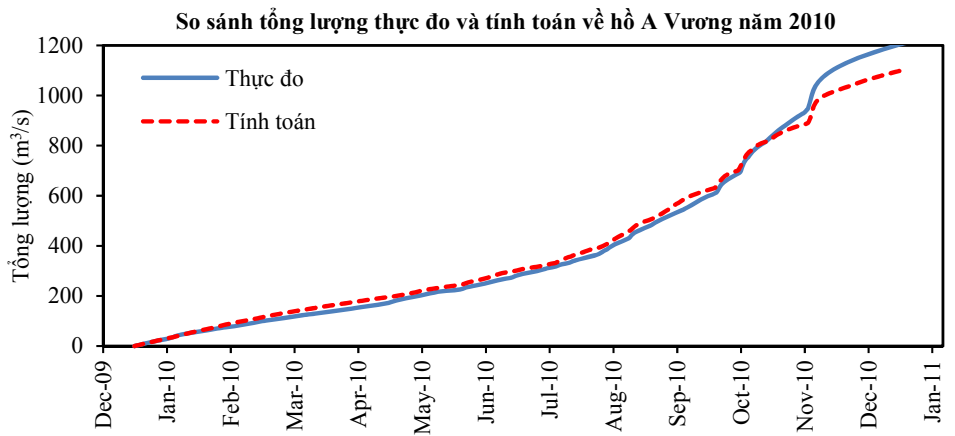

Hình 4. Kết quả so sánh giũua đường tổng luợng tính toán và thực đo năm 2010

Việc mô phỏng quá trình lũ năm 2010 đạt kết quả khá tốt, tại trạm hiệu chỉnh đường quá trình tính toán và thực đo khá phù hợp cả về giá trị đỉnh và hình dạng lũ, chỉ tiêu Nash-Sutcliffe đạt $81,1 \%$, sai số tổng lượng là $\mathrm{WBL}=8,8 \%$. Từ kết quả trên, ta có thể sử dụng bộ thông số của mô hình để phục vụ cho quá trình kiểm định tiếp theo.

\section{b) Kiểm định mô hình}

Sử dụng bộ thông số của mô hình vừa tìm được ở phần hiệu chỉnh phía trên để tiến hành kiểm định với quá trình lũ năm 2011, 2013. Kết quả so sánh giữa quá trình tính toán và thực đo được thể hiện trên hình 5 đến hình 8 . 


\section{BÀI BÁO KHOA HỌC}

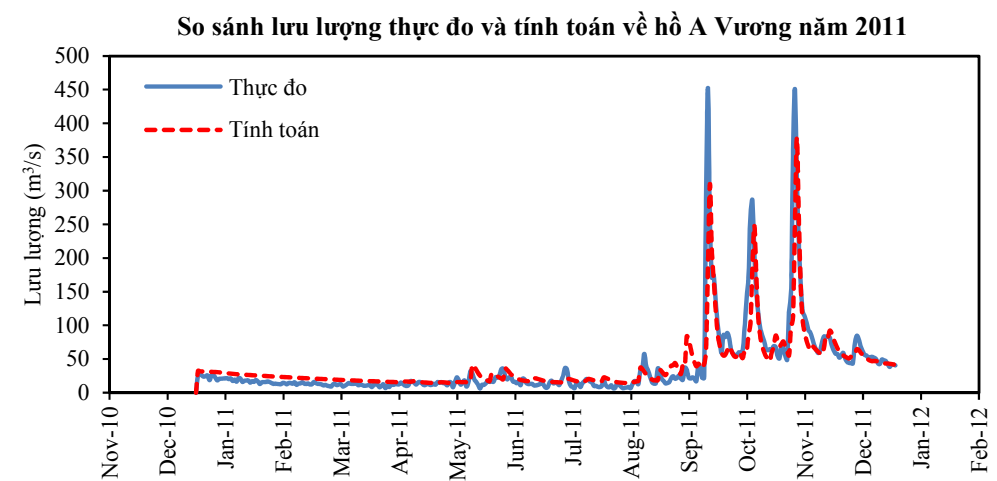

Hình 5. Kết quả so sánh giữa đường quá trình tính toán và thực đo năm 2011

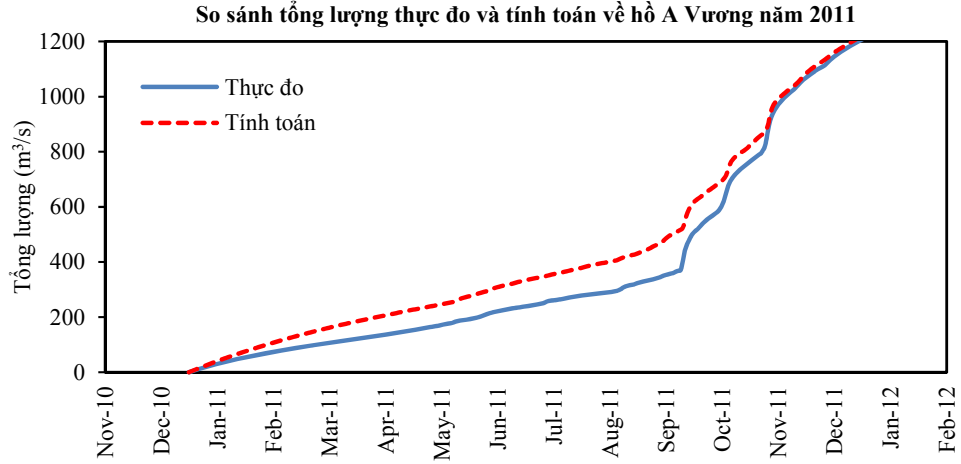

Hình 6. Kết quả so sánh giữa đường tổng lương tính toán và thực đo năm 2011

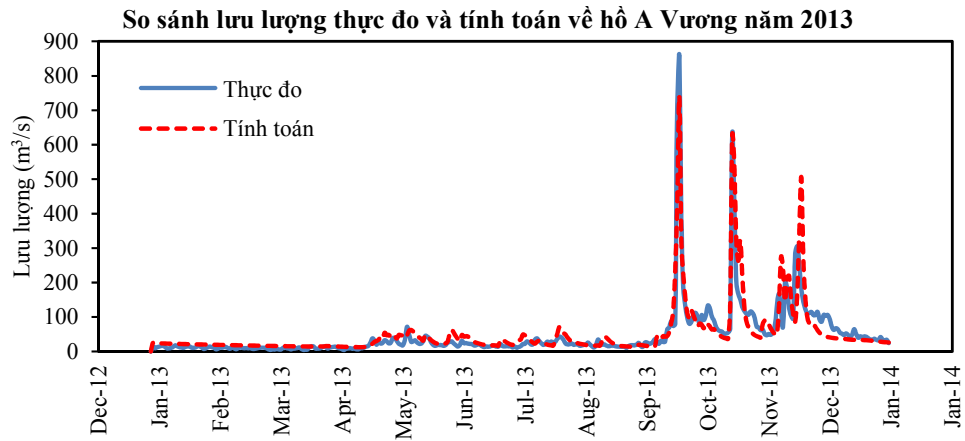

Hình 7. Kết quả so sánh giũa đường quá trình tính toán và thực đo năm 2013

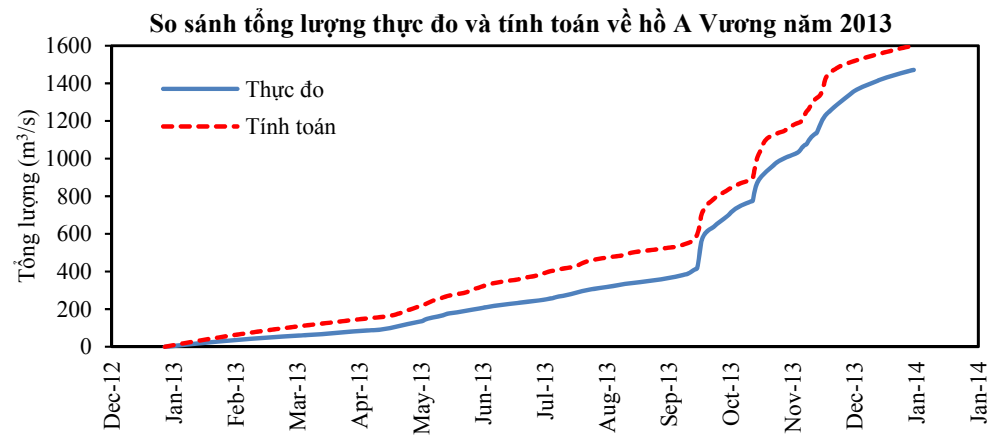

Hình 8. Kết quả so sánh giũa đường tổng lương tính toán và thực đo năm 2013

Việc mô phỏng quá trình lũ năm 2011, 2013 đạt kết quả khá tốt, tại trạm kiểm định đường quá tính toán và thực đo khá phù hợp cả về hình dạng lũ, chỉ tiêu Nash-Sutcliffe năm 2011, 2013 lần lượt đạt $71,6 \%$ và $76,6 \%$; sai số tổng lượng lần lượt là là $1 \%$ và $8,8 \%$. Từ kết quả trên, ta có thể sử dụng bộ thông số của mô hình (Bảng 1) để phục vụ cho quá trình tính toán tiếp theo. 
Bảng 1. Bộ thông số mô hình NAM sau khi hiệu chinh và kiểm định

\begin{tabular}{cccccc}
\hline$U_{\max }$ & 10,3 & $C K_{I F}$ & 570 & $T_{I F}$ & 0,25 \\
\hline$L_{\max }$ & 100 & $C K_{I, 2}$ & 33,6 & $T_{G}$ & 0,25 \\
$C Q_{O F}$ & 0,34 & $T_{O F}$ & 0,71 & $C K_{B F}$ & 3574 \\
\hline
\end{tabular}

3.2. Đánh giá ảnh hưởng của biến đổi khí hậu đến dòng chảy đến hồ A Vương

Nhằm đánh giá ảnh hưởng của biến đổi khí hậu đến dòng chảy đến hồ $\mathrm{A}$ vương, nghiên cứu dựa trên kịch bản $\mathrm{BĐKH} \mathrm{của} \mathrm{Bộ} \mathrm{tài} \mathrm{nguyên} \mathrm{và}$ Môi trường năm 2016 với 2 kịch bản $\mathrm{RCP} 4.5$ và RCP8.5 [1]. Sử dụng mô hình MIKE-NAM đã được tìm bộ thông số phù hợp qua các bước hiệu chỉnh và kiểm định ở trên để mô phỏng dòng chảy cho các thời kỳ 2016 - 2035, 2046 - 2065, 2080 - 2099. Dựa trên sự biến động lượng mưa theo các mùa của khu vực được trích từ phụ lục A trong kịch bản BĐKH năm 2016 của Bộ tài nguyên và Môi trường, tiến hành tính toán dòng chảy trên lưu vực hồ A Vương theo các kịch bản BĐKH ứng với các thời kỳ khác nhau. Sau khi tính toán được lượng mưa thay đổi so với thời kỳ nền, tiến hành nhập lượng mưa mới vào mô hình NAM để tính toán ra dòng chảy theo các kịch bản $\mathrm{BĐKH.} \mathrm{Kết} \mathrm{quả} \mathrm{tính} \mathrm{toán} \mathrm{dòng} \mathrm{chảy}$ đến hồ từ mô hình theo các kịch bản $\mathrm{BĐKH}$ được thể hiện như sau:

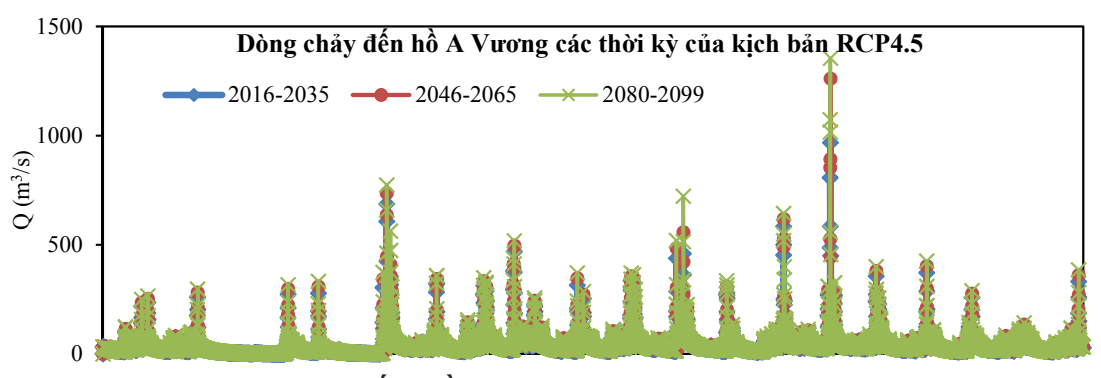

Hình 9. Quá trình lưu lương đến hồ A Vuơng qua các thời kỳ theo kịch bản RCP4.5

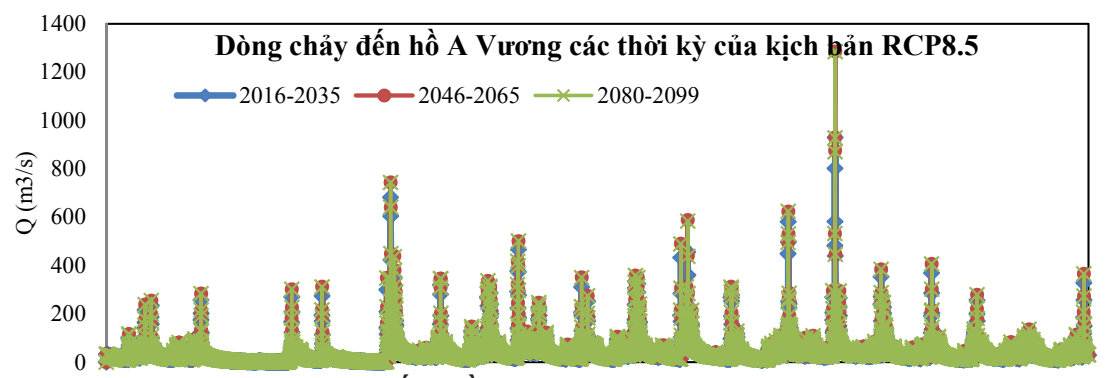

Hình 10. Quá trình lưu lương đến hồ A Vuơng qua các thời kỳ theo kịch bản RCP8.5

a) Đánh giá tác động của BĐKH đến dòng chảy năm

Dựa trên kết quả tính toán dòng chảy đến hồ A Vương theo các kịch bản biến đổi khí hậu, nhận thấy dòng chảy trung bình năm trong các thời kỳ tương lai đều có xu thế tăng so với thời kỳ nền, được thể hiện hình 11a-b.

Dòng chảy năm đến hồ tăng dần theo các thời kỳ theo các kịch bản $\mathrm{BĐKH,} \mathrm{tăng} \mathrm{lên} \mathrm{so} \mathrm{với} \mathrm{thời}$ kỳ nền và thời kỳ sau lớn hơn thời kỳ trước. Theo kịch bản RCP4.5, dòng chảy trung bình năm có mức tăng thấp hơn so với kịch bản RCP8.5. Sự thay đổi này phù hợp với sự thay đổi của lượng mưa và bốc hơi trên lưu vực theo các kịch bản khác nhau. b) Đánh giá tác động của BĐKH đến dòng chảy lũ

Mùa lũ trên lưu vực hồ $\mathrm{A}$ Vương kéo dài từ tháng IX - XII. Theo các kịch bản BĐKH, dòng chảy mùa lũ có xu hướng tăng lên so với thời kỳ nền. Nhìn chung, dòng chảy mùa lũ theo kịch bản RCP8.5 có mức gia tăng lớn hơn so với kịch bản RCP4.5. Xu thế của dòng chảy lũ so với thời kỳ nền phù hợp với sự thay đổi của lượng mưa và bốc hơi trên lưu vực theo các kịch bản khác nhau (Hình 12 và Hình 13).

Thời kỳ 2016 - 2035: Theo kết quả tính toán của mô hình cho thấy mức độ biến đổi dòng chảy lũ đều có xu hướng tăng lên so với thời kỳ nền, đồng thời giữa các kịch bản có sự chênh lệch 


\section{BÀI BÁO KHOA HỌC}

theo mức biến đổi của lượng mưa.

Thời kỳ 2046 - 2065: Dòng chảy mùa lũ tại các trạm đều tăng so với thời kỳ nền, và có xu hướng lớn hơn thời kỳ trước theo các kịch bản. Tuy nhiên giữa các kịch bản có sự chênh lệch theo mức biến đổi của lượng mưa.

Thời kỳ 2080 - 2099: Lưu lượng dòng chảy lũ tăng khá rõ rệt so với thời kỳ nền, giữa các kịch bản có sự chênh lệch theo mức biến đổi của lượng mưa.

c) Đánh giá tác động của BĐKH đến dòng chảy mùa cạn

Theo kết quả tính toán của các kịch bản $\mathrm{BĐKH}$, dòng chảy mùa cạn có sự khác biệt đáng kể theo từng thời kỳ và theo từng kịch bản BĐKH.

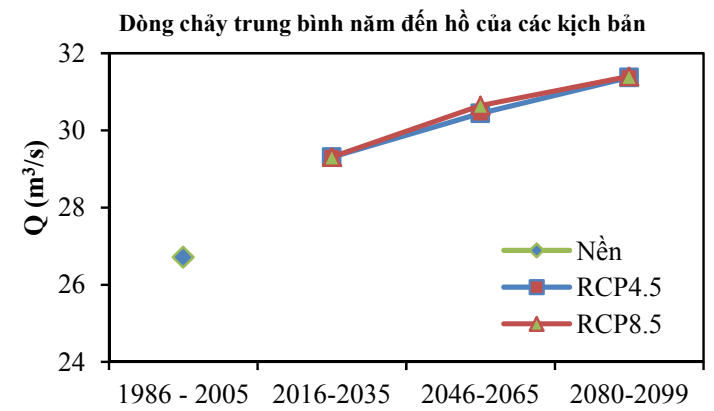

Hình 11a. Dòng chảy trung bình năm đến lưu vưc hồ A Vương

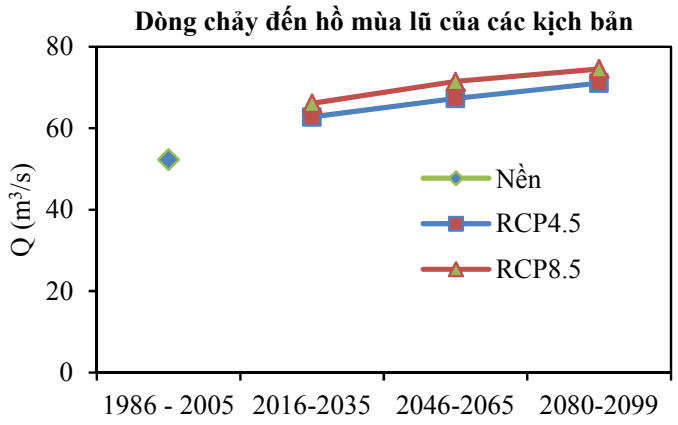

Hình 12. Dòng chảy trung bình mùa lũ đến lưu vuec hồ A Vương

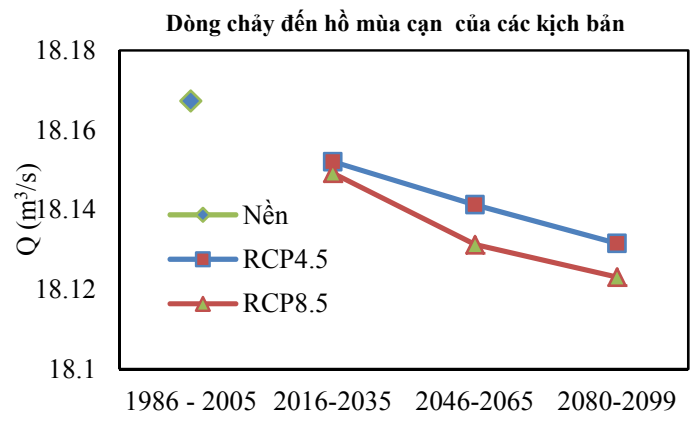

Hình 14. Dòng chảy trung bình mùa cạn đến lưu vưc hồ A Vương

TAP CHÍ KHÍ TƯợNG THỦY VĂN

Số tháng 04 - 2019
Thời kỳ 2016 - 2035: Dòng chảy mùa cạn đến hồ có xu hướng giảm so với thời kỳ nền và kịch bản RCP8.5 có xu hướng giảm so với kịch bản RCP4.5.

Thời kỳ 2046 - 2065: Dòng chảy mùa cạn có xu hướng giảm so với thời kỳ trước. Theo kịch bản RCP8.5 có xu hướng giảm nhiều hơn so với kịch bản RCP4.5.

Thời kỳ 2080 - 2099: Dòng chảy mùa cạn có xu hướng giảm so với thời kỳ nền, kịch bản RCP8.5 có xu thế giảm mạnh hơn so với kịch bản RCP4.5.

Nhìn chung, kết quả tính toán của mô hình phù hợp với sự biến đổi về lượng mưa theo từng thời kỳ và theo từng kịch bản $\mathrm{BĐKH} \mathrm{khác} \mathrm{nhau.}$

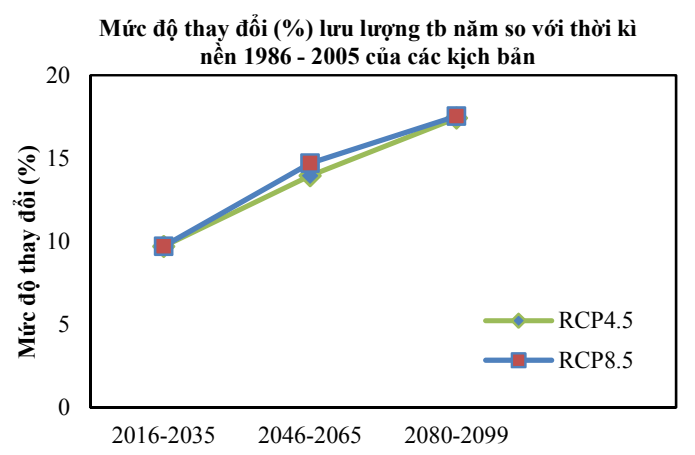

Hình 11b. Mức thay đổi dòng chảy trung bình năm đến hồ $A$ Vương

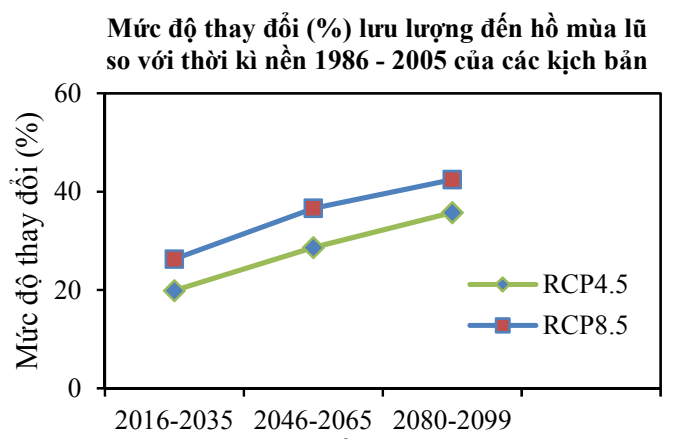

Hình 13. Mức thay đổi dòng chảy trung bình mùa lũ đến lư vực hồ A Vưong

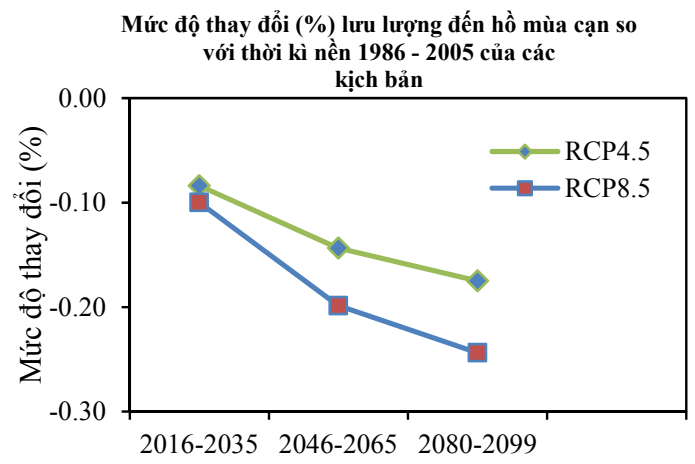

Hình 15. Mức thay đổi dòng chảy trung bình mùa cạn đến lưu vục hồ A Vương 
d) Tác động của BĐKH đến dòng chảy tháng

Xét về phân phối dòng chảy tháng, dòng chảy đến hồ có xu hướng tăng nhẹ trong các tháng mùa xuân, giảm dần trong các tháng mùa hè, các tháng mùa lũ có xu hướng tăng mạnh thể hiện ở hình 16 và hình 17.

Theo kết quả tính toán cho thấy, sự thay đổi dòng chảy đến hồ có sự thay đổi theo các tháng của từng mùa. Tháng $\mathrm{V}$ là tháng chịu tác động mạnh mẽ nhất của $\mathrm{BĐKH} \mathrm{trong} \mathrm{các} \mathrm{tháng} \mathrm{mùa}$ cạn. Tháng XI là tháng chịu tác động mạnh mẽ nhất trong các tháng mùa lũ. Mức độ ảnh hưởng của $\mathrm{BĐKH} \mathrm{lên} \mathrm{dòng} \mathrm{chảy} \mathrm{mùa} \mathrm{kiệt} \mathrm{là} \mathrm{ít} \mathrm{hơn} \mathrm{so}$ với mùa lũ.

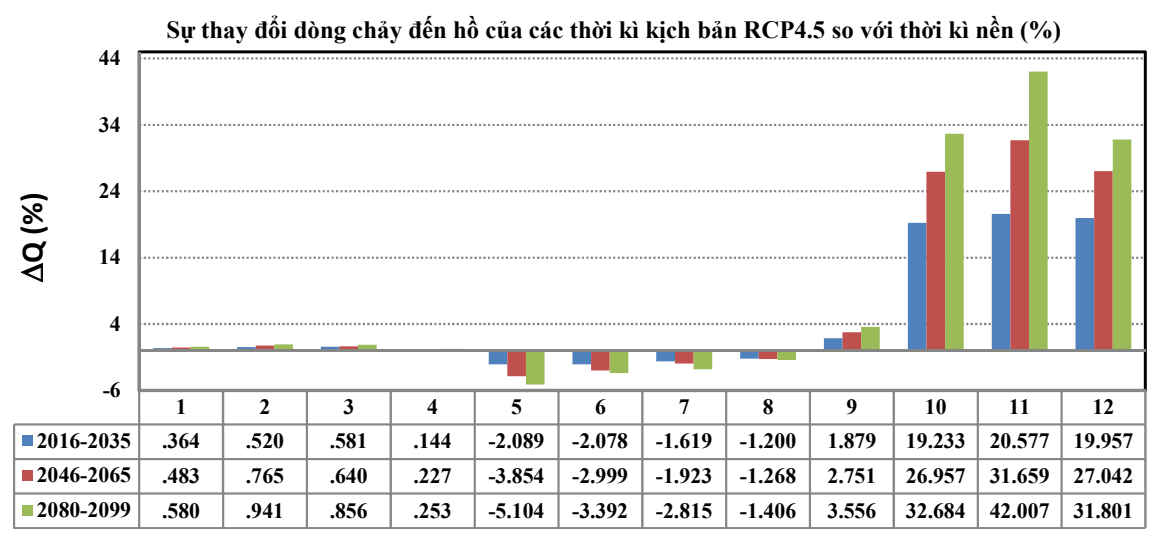

Hình 16. Sự thay đổi dòng chảy đến hồ A Vương của các thời kì kịch bản RCP4.5 so với thời kì nền

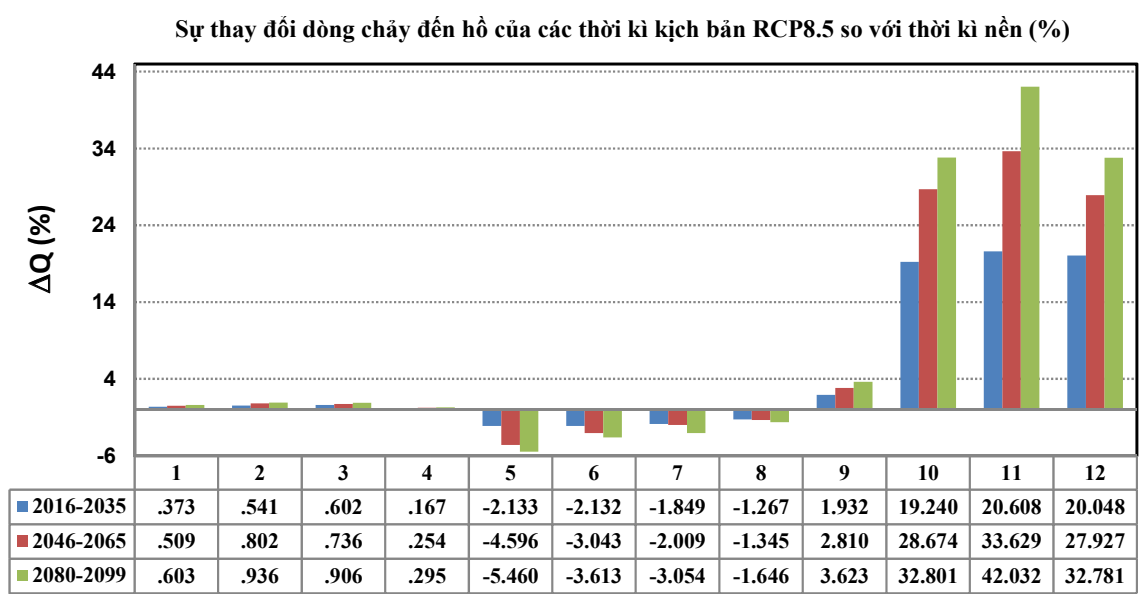

Hình 17. Sự thay đổi dòng chảy đến hồ A Vương của các thời kì kịch bản RCP8.5 so với thời kì nền

e) Tác động của BĐKH đến đỉnh lũ và tổng lượng lũ lưu vưc hồ A Vương

Để đánh giá ảnh hưởng của biến đổi khí hậu đến đỉnh lũ và tổng lượng lũ thiết kế đến hồ $\mathrm{A}$ Vương, trong nghiên cứu tính toán dựa trên thay đổi lượng mưa ngày lớn nhất và tổng lượng mưa ngày lớn nhất thời đoạn (3 ngày, 5 ngày, 7 ngày, 9 ngày) của các thời kỳ. Hai trận lũ thiết kế ứng với tần suất $\mathrm{P}=0,1 \%$ và $\mathrm{P}=0,5 \%$ được chọn làm mẫu điển hình tính toán. Từ đường quá trình lũ hiện trạng được chọn, thông qua các hệ số thu phóng $K_{i}$ (hệ số đỉnh lũ, tổng lượng 3 ngày, tổng lượng 5 ngày, tổng lượng 7 ngày, tổng lượng 9 ngày) sẽ xác định được quá trình lũ các thời kỳ của các kịch bản RCP4.5 và RCP8.5 (Hình 18 và Hình 19).

Từ chuỗi lưu lượng tức thời tháng của các thời kỳ của các kịch bản $\mathrm{BĐKH,} \mathrm{xác} \mathrm{định} \mathrm{các}$ giá trị lưu lượng tức thời lớn nhất tương ứng với các thời kỳ. Từ các giá trị đó, xác định được các hệ số thu phóng đỉnh lũ dưới tác động của $\mathrm{BĐKH}$ cho từng thời kỳ của các kịch bản tương lai (bảng 2). Từ đó tính được lưu lượng đỉnh lũ thiết kế ứng với từng tần suất dưới tác động của $\mathrm{BĐKH}$ từng thời kỳ của các kịch bản tương lai (Bảng 3, 4). 


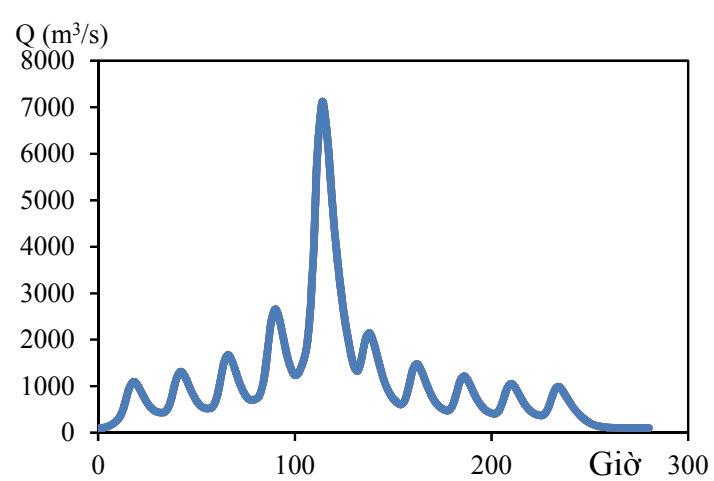

Hình 18. Quá trình lũ thiết kế lưu vục A Vuơng ung vớ $P=0,1 \%$

Bảng 2. Hệ số thu phóng đỉnh lũ (D) dưới tác động của biến đổi khi hậu

\begin{tabular}{ccccc}
\hline \multirow{2}{*}{ Thời kỳ } & $1986-$ & $2016-$ & $2046-$ & $2080-$ \\
& 2005 & 2035 & 2065 & 2099 \\
\hline \multirow{2}{*}{$R C P 4.5$} & nền & 1.221 & 1.294 & 1.344 \\
$R C P 8.5$ & nền & 1.211 & 1.304 & 1.302 \\
\hline
\end{tabular}

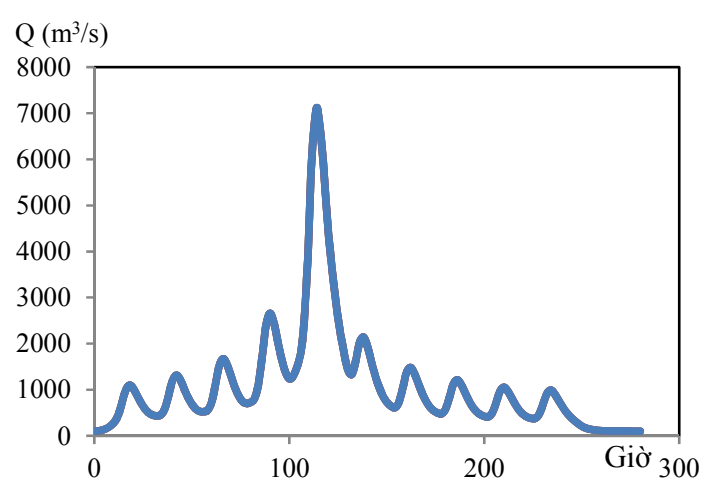

Hình 19. Quá trình lũ thiết kế lưu vực A Vurong úng với $P=0,5 \%$

Bảng 3. Lư lượng đỉnh lũ thiết kế $P=0.1 \%$ trong các thời kỳ $B Đ K H$

\begin{tabular}{ccccc}
\hline \multirow{2}{*}{ Thời kỳ } & $\begin{array}{c}1986- \\
2005\end{array}$ & $\begin{array}{c}2016- \\
2035\end{array}$ & $2046-$ & $2060-$ \\
& 2095 & 2099 \\
\hline$R C P 4.5$ & 7120 & 8693.52 & 9213.28 & 9569.28 \\
$R C P 8.5$ & 7120 & 8366 & 9284.48 & 9270.24 \\
\hline
\end{tabular}

Bảng 4. Lưu luợng đỉnh lũ thiết kế $P=0.5 \%$ trong các thời kỳ BĐKH

\begin{tabular}{ccccc}
\hline \multirow{2}{*}{ Thời kỳ } & $1986-$ & $2016-$ & $2046-$ & $2080-$ \\
& 2005 & 2035 & 2065 & 2099 \\
\hline$R C P 4.5$ & 5720 & 6984.12 & 7401.68 & 7687.68 \\
$R C P 8.5$ & 5720 & 6721 & 7458.88 & 7447.44 \\
\hline
\end{tabular}

\section{Kết luận}

Qua xem xét, phân tích và đánh giá nhận thấy dưới tác động của biến đổi khí hậu, dòng chảy đến hồ $\mathrm{A}$ Vương có nhiều biến đổi. So với thời kì nền, lượng dòng chảy trung bình năm và lượng dòng chảy mùa lũ đến hồ có xu hướng tăng qua các thời kì. Đặc biệt là kịch bản RCP 8.5 ứng với thời kì 2080 - 2099 có mức tăng rõ rệt nhất. Sự chênh lệch về lượng dòng chảy thì tương ứng với sự biến đồi về lượng mưc theo các kịch bản. Dòng chảy mùa cạn đến hồ $\mathrm{A}$ Vương trong tương lai có xu thế giảm so với thời kì nền, kịch bản RCP 8.5 giảm mạnh hơn so với kịch bản RCP4.5 trong các thời kì tính toán. Xét về phân phối dòng chảy tháng, dòng chảy đến hồ có xu hướng tăng nhẹ trong các tháng mùa xuân, giảm dần trong các tháng mùa hè, các tháng mùa lũ có xu hướng tăng mạnh. Tháng $\mathrm{V}$ là tháng chịu tác động mạnh mẽ nhất của BĐKH trong các tháng mùa cạn. Tháng XI là tháng chịu tác động mạnh mẽ nhất trong các tháng mùa lũ. Mức độ ảnh hưởng của $\mathrm{BĐKH}$ lên dòng chảy mùa kiệt là ít hơn so với mùa lũ.

Để có thể nâng cao khả năng ứng phó với $\mathrm{BĐKH}$, nhằm đảm bảo cho sự phát triển bền vững trên lưu vực hồ thủy điện $\mathrm{A}$ Vương trong từng giai đoạn cụ thể, cần có những định hướng chính sách, dự án, nâng cao nhận thức về biến đổi khí hậu cũng như ứng phó với biến đổi khí hậu của cộng đồng, các ngành, các cấp chính quyền. Kết quả của bài báo là cơ sở để giúp các nhà quản lý, các nhà hoạch định chính sách và các địa phương trong vùng nghiên cứu xây dựng các kế hoạch, phương án, giải pháp ứng phó thích hợp nhằm giảm nhẹ các tác động bất lợi do ảnh hưởng của biến đổi khí hậu và xâm nhập mặn trong tương lai.

Lời cảm onn: Với sự giúp đỡ và hướng dẫn tận tình của thầy GS.TS. Trần Thục. Bài báo này là một phần kết quả của luận văn thạc sỹ của học viên Nguyễn Văn Khánh với tên đề tài luận văn: "Nghiên cưu tác động của biến đổi khí hậu đến dòng chảy đến hồ phuc vu vận hành hồ thưy điện $A$ Vuong tỉnh Quảng Nam”. 


\title{
Tài liệu tham khảo
}

1. Bộ Tài nguyên và Môi trường (2016), Kịch bản biến đổi khí hậu và nước biển dâng cho Việt Nam.

2. Phạm Ngọc Rư, Trần Vũ, Lê Nguyên Trung (2014), Đánh giá tác động của BĐKH đến lĩnh vưc Thưy điện và đề xuất các giải pháp ứng phó.

3. Vũ Văn Minh, Nguyễn Hoàng Minh, Trần Hồng Thái, (2011), Đánh giá tác động của Biến đổi khi hậu đến dòng chảy lũ lưu vực sông Hồng - Thái Bình. Tuyển tập Báo cáo Khoa học lần thứ XIII, tr. $72-78$.

4. Trần Thanh Xuân, Hoàng Minh Tuyển, Lê Tuấn Nghĩa, Lương Hữu Dũng (2011), Tác động của Biến đổi khi hậu đến dòng chảy trong sông. Tuyển tập Báo cáo Khoa học lần thứ XIII, tr. 146153.

5. Nguyễn Ý Như, (2011), Nghiên cưu tác động của biến đổi khí hậu đến cực trị dòng chảy trên luu vực sông Nhuệ Đáy thuộc thành phố Hà Nội.

6. DHI, (2007). MIKE 11 - User's Manual.

7. DHI, (2007). MIKE 11 - User's Manual Feddes, R.A., M. Menenti, and P. Kabat, 1989. Modeling the soil water and surface energy balance in relation to climate models, European coordination group on land - surface processes, hydrology, Dessertification in Europe, Barcelona, pp. 21.

\section{RESEARCH ABOUT ASSESSING CLIMATE CHANGE IMPACTS ON THE FLOW INTO AVUONG LAKE}

\author{
Nguyen Van Khanh', Tran Thuc ${ }^{2}$ \\ ${ }^{1}$ The Central Hydrometeorological Station of Central Vietnam \\ ${ }^{2}$ Viet Nam Institute of Meteorology, Hydrology and Climate Change
}

\begin{abstract}
The NAM model has been applied in this research to calculate and evaluate the effects of climate change to A Vurong lake. The correction and inspection result indicates the similarities of phase and amplitude fluctuations between calculation and measurement flow. Base on the editing and testing results, the changes in flow come to lake in the future periods will be predict. The calculation results of flow to the lake in future periods show that the flow changes according to the months of each season: the May is affected the most powerful by climate change in the dry months, and November is affected the most powerful in the flood months. The degree of influence of climate change to the dry season is less than the flood season.
\end{abstract}

Keywords: MIKE NAM, A Vuong, Climate change. 